\title{
Inflammatory Biomarkers and Endothelial Dysfunction among Obese Patients with Type 2 Diabetes: A Correlational Study
}

\author{
Saiem Al-Dahr MH* \\ Department of Medical Laboratory Technology, King \\ Abdulaziz University, Saudi Arabia \\ *Corresponding author: Mohammed H. Saiem Al- \\ Dahr, Department of Medical Laboratory Technology, \\ Faculty of Applied Medical Sciences, King Abdulaziz \\ University, P.O. Box 80324, Jeddah, 21589, Saudi Arabia
}

Received: February 04, 2017; Accepted: April 07, 2017; Published: April 25, 2017

\begin{abstract}
Background: Systemic inflammation and endothelial dysfunction induce vascular complications of diabetes mellitus that impose a huge burden on diabetes mellitus complications management.
\end{abstract}

Objective: The aim of the present study was to investigate the possible relationship between systemic inflammation and endothelial dysfunction in obese patients with type 2 diabetes.

Materials and Methods: Forty obese patients with type 2 diabetes (24 males and 16 females) with body mass index (BMI) ranged from 31 to $35 \mathrm{Kg} /$ $\mathrm{m} 2$, non smokers, free from respiratory, kidney; liver, metabolic and neurological disorders participated in this randomized controlled trial. Their age ranged from 40 to 55 years were randomly included in this study as the first group (A). While a forty non-diabetic subjects (23 males and 17 females) not suffering of any disease, their age ranged from 40 to 52 years were included in this study as the second group (B) and considered as a control group.

Results: Diabetic patients showed significantly higher values of TNF- $\alpha$, IL-6, CRP, HBA1c, ICAM-1, VCAM-1 and E-selectin in comparison to controls. Also, there was significant positive correlation between inflammatory and endothelial dysfunction biomarkers among obese diabetic patients.

Conclusion: There was a strong association between elevated biomarkers of systemic inflammation and endothelial dysfunction among obese patients with type 2 diabetes.

Keywords: Endothelial dysfunction; Inflammatory cytokine; Obesity; Noninsulin dependent diabetes mellitus

\section{Introduction}

Diabetes mellitus (DM) is a major medical problem worldwide. The World Health Organization (WHO) stated that about 350 million diabetic subjects all over the world and this number will be the double by 2030 [1], these numbers proved that there is a need for novel therapeutic intervention for both diabetes prevention and treatment [2]. However, obesity and diabetes are becoming pandemic and pose a major risk for several comorbidities as cardiovascular disorders. Adipose tissue is considered as an active endocrine tissue that secretes cytokines which contribute to atherosclerosis and systemic inflammation which may contribute to the etiology of type 2 diabetes [3].

Obesity is associated with low-grade of systemic inflammation and disorder in production of adipocytokines that were involved in the pathogenesis of type 2 diabetes related cardiovascular disorders [4-5] which increased the mortality rate among the diabetic patients [6]. Increased serum levels of markers of systemic inflammation e.g. interleukin-6 (IL-6), tumor necrosis factor- $\alpha$ (TNF- $\alpha$ ) and C-reactive protein (CRP) are usually associated with increased morbidity and mortality among type 2 diabetic patients [7-11].
Elevated serum levels of inflammatory markers in type 2 diabetic patients lead to endothelial cell dysfunction [12,13], which may be induced by hyperlipidemia, hyperinsulinemia and pancreatic $\beta$-cell failure leading to [13]. Insulin regulates vascular function by stimulation of the expression of vascular cell adhesion molecule (soluble vascular cell adhesion molecule-1 (VCAM-1), soluble intercellular cell adhesion molecule-1 (ICAM-1) and E-selectin on endothelium. So, endothelial dysfunction is associated with insulin resistance [14]. Endothelial dysfunction is characterized by prothrombic properties, pro-inflammatory state and reduced vasodilation $[15,16]$.

The aim of this study was to detect the relationship between systemic inflammation markers, endothelial dysfunction in obese Saudi patients with type 2 diabetes mellitus.

\section{Materials and Methods}

\section{Subjects}

Forty non-smokers obese type 2 diabetic patients visiting king Abdulaziz University Hospital, Jeddah, Saudi Arabia, were included in this randomized controlled study. The mean age was $47.73 \pm 6.87$ year and mean body mass index was $33.11 \pm 2.25 \mathrm{~kg} / \mathrm{m}^{2}$ who 
Table 1: This table demonstrates the mean value of clinical and laboratory parameters for all participants in the two groups.

\begin{tabular}{|l|c|c|c|c|}
\hline \multirow{2}{*}{} & \multicolumn{2}{|c|}{ Mean+SD } & \multirow{2}{*}{ T-value } & \multirow{2}{*}{ Significance } \\
\cline { 2 - 3 } & Diabetic group & Control group & & \\
\hline Age (year) & $47.73 \pm 6.87$ & $35.40 \pm 6.05$ & 5.42 & $\mathrm{P}<0.05$ \\
\hline BMI $\left(\mathrm{kg} / \mathrm{m}^{2}\right)$ & $33.11 \pm 2.25$ & $26.58 \pm 2.97$ & 4.52 & $\mathrm{P}<0.05$ \\
\hline FBS $(\mathrm{mg} / \mathrm{dl})$ & $180.32 \pm 14.45$ & $87.63 \pm 6.75$ & 9.87 & $\mathrm{P}<0.05$ \\
\hline PPS $(\mathrm{mg} / \mathrm{dl})$ & $253.67 \pm 21.46$ & $105.92 \pm 15.21$ & 8.95 & $\mathrm{P}<0.05$ \\
\hline
\end{tabular}

BMI: Body Mass Index; FBS: Fasting Blood Sugar; PPS: Postprandial Blood Sugar

Table 2: This table illustrates the mean value and significance of inflammatory markers, Glycosylated Hemoglobin, and cellular adhesion molecules TNF- $\alpha$, IL6 , CRP, HBA1c (\%), ICAM-1, VCAM-1, E-selectin in both diabetic (A) and contro group (B).

\begin{tabular}{|l|c|c|c|c|}
\hline & \multicolumn{2}{|c|}{ Mean+SD } & \multirow{2}{*}{ T-value } & Significance \\
\cline { 2 - 5 } & Diabetic group & Control group & & \\
\hline TNF- $\alpha(\mathrm{pg} / \mathrm{mL})$ & $5.93 \pm 1.57$ & $4.10 \pm 1.52$ & 5.43 & $\mathrm{P}<0.05$ \\
\hline CRP $(\mathrm{mg} / \mathrm{dl})$ & $16.34 \pm 3.22$ & $10.16 \pm 2.61$ & 6.25 & $\mathrm{P}<0.05$ \\
\hline IL-6 $(\mathrm{pg} / \mathrm{mL})$ & $8.27 \pm 2.15$ & $5.11 \pm 1.85$ & 5.76 & $\mathrm{P}<0.05$ \\
\hline HBA1c $(\%)$ & $9.13 \pm 2.15$ & $6.05 \pm 0.87$ & 6.13 & $\mathrm{P}<0.05$ \\
\hline ICAM-1 $(\mathrm{ng} / \mathrm{ml})$ & $94.65 \pm 11.23$ & $81.17 \pm 9.16$ & 7.45 & $\mathrm{P}<0.05$ \\
\hline VCAM-1 $(\mathrm{ng} / \mathrm{ml})$ & $832.31 \pm 46.11$ & $724.16 \pm 38.22$ & 9.27 & $\mathrm{P}<0.05$ \\
\hline E-selectin $(\mathrm{ng} / \mathrm{ml})$ & $14.89 \pm 6.02$ & $8.71 \pm 3.51$ & 5.84 & $\mathrm{P}<0.05$ \\
\hline
\end{tabular}

TNF-a: Tumor Necrosis Factor-Alpha; IL-6: Interleukin-6; CRP: C-Reactive Protein; HBA1c: Glycosylated Hemoglobin; ICAM-1: Inter-Cellular Adhesion Molecule; VCAM-1: Vascular Cell Adhesion Molecule

participated in the current study as group (A). Initially, a physician at King Abdulaziz University Hospital examined all participants their medical history was taken to collect information about general condition, physical activity and current medications if any. All subjects with any pulmonary disorders, cardiovascular conditions as uncontrolled hypertension, congenital and rheumatic heart diseases were excluded from the study. In the other hand another forty agematched non-diabetic healthy subjects were participated in the study as a control group (B). This study was approved by the Scientific Research Ethical Committee, Faculty of Applied Medical Sciences at King Abdulaziz University and all participants signed a written informed consent.

\section{Sample processing}

Blood samples were collected in the morning after at least $10 \mathrm{~h}$ fasting hemolyzed and lipemic samples were excluded. Whole blood Samples were centrifuged (at $3500 \mathrm{rpm}$ for 5 minutes), to separate the serum and plasma. All samples were stored after centrifugation at $-80^{\circ} \mathrm{C}$ until time of processing. These samples were collected in three different vacutainer tubes (BD vacutainer). One tube for measuring CRP levels, glucose concentration and IL-6, the second tube contains Lithium Heparin to measure, soluble E-selectin (sE-selectin) and soluble inter-cellular adhesion molecule 1 (sICAM-1, VAM-1), TNF- $\alpha$, and where the third tube contains EDTA K2, EDTA K3 for measuring Glycosylated Hemoglobin ( $\mathrm{HbA} 1)$.

Biochemical parameters: Biochemical parameters including serum Glucose, Glycosylated Hemoglobin $\left(\mathrm{HbA1}_{\mathrm{C}}\right)$ and CRP all were measured at the same time after collection. Fasting serum glucose
Table 3: Pearson's correlation coefficients test value of the studied variables in the diabetic group.

\begin{tabular}{|c|c|c|c|}
\hline & ICAM-1 (ng/ml) & VCAM-1 (ng/ml) & E-selectin (ng/ml) \\
\hline TNF- $\alpha(p g / m L)$ & $0.875^{\star * *}$ & $0.767^{* * *}$ & $0.618^{* *}$ \\
\hline IL-6 (pg/mL) & $0.635^{* *}$ & $0.792^{* * *}$ & $0.753^{* \star * t}$ \\
\hline $\mathrm{CRP}(\mathrm{mg} / \mathrm{dl})$ & $0.914^{* * *}$ & $0.584^{* *}$ & 0.881 \\
\hline HBA1c (\%) & $0.473^{*}$ & $0.519^{* *}$ & $0.476^{*}$ \\
\hline
\end{tabular}

TNF-a: Tumor Necrosis Factor-Alpha; IL-6: Interleukin-6; CRP: C-Reactive Protein; HBA1c: Glycosylated Hemoglobin; ICAM-1: Inter-Cellular Adhesion Molecule; VCAM-1: Vascular Cell Adhesion Molecule; Spearman's correlation was used *: $P<0.05^{* *}: P<0.01^{* * *}: P<0.001$.

concentration, $\mathrm{HbAl}_{\mathrm{C}}$ and CRP were quantified by enzymaticcolorimetric methods using commercially available kits (Roche Diagnostics, Mannheim, Germany) at king Abdul-Aziz University Hospital. For postprandial protocol, after a $10 \mathrm{~h}$ overnight fasting, the subjects in both groups consumed a liquid made of $50 \mathrm{~g}$ Dextrose (Thermo scientific, USA), blood samples were collected in the fasting state and after $2 \mathrm{~h}$. Plasma and serum were immediately separated by centrifugation and processed as before.

Measurement of biomarkers of endothelial and inflammatory cytokines: Biomarkers of endothelial function included adhesion molecules (ICAM-1 and VCAM-1), soluble E-selectin, and inflammatory cytokines such as tumor necrosis factor-alpha (TNF- $\alpha$ ), and Interleukin-6 (IL-6) levels were measured from frozen plasma samples stored at $-80{ }^{\circ} \mathrm{C}$. Enzyme-linked immunosorbent assays kits (ELISAs) were used to measure soluble levels of ICAM-1 and VCAM1, sE-selectin, (TNF- $\alpha$ ), and IL-6 (GE Healthcare Amersham, Biotrak Easy ELISA), which employs the quantitative sandwich enzyme immunoassay technique.

\section{Statistical analysis}

Independent t-test was used to compare mean differences between both groups. Statistical analysis of data was performed using SPSS (Chicago, IL, USA) version 17. The degree of correlation systemic inflammation, endothelial dysfunction in obese patients with type 2 diabetes was detected by Pearson's product moment correlation coefficients (r).

\section{Results}

The mean values of the clinical and laboratory parameters variables for participants in the two groups have a statistical significant difference as presented in (Table 1). The data that have been computed in (Table 2) summarizes the comparison between patients and matched controls. Diabetic patients showed significantly higher values of TNF- $\alpha$, IL-6, CRP, HBA1c, ICAM-1, VCAM- 1 and E-selectin in comparison to controls. However, (Table 3) represents correlation coefficient $(r)$ between studied parameters in diabetic patients, significant positive correlations were found between TNF- $\alpha$, IL-6, CRP, HBA1c and ICAM-1, VCAM-1, E-selectin.

\section{Discussion}

Currently, the steady rising medico-social burden of type 2 diabetes is positively correlated to the vascular system co-morbidities, there is 4 -fold increase in the rate of ischemic heart disease, a 10 -fold increase in rate of peripheral vascular disorders, and a 3- to 4-fold increase of mortality rate with about $75 \%$ of diabetic patients dying by 
vascular disorders $[17,18]$. The principal findings of our study are that higher levels of BMI, HBA1c, IL-6, TNF- $\alpha$, CRP were associated with higher levels of E-selectin levels in type 2 diabetics. Our findings are consistent with many studies which reported a significant association between diabetes and elevated CRP $[19,20]$. However, Swellam, et al. stated that elevated levels of CRP can be used for early diagnosis of non-insulin dependent diabetes mellitus and can predict diabetic complications [21]. Also Pradhan, et al. concluded that elevated levels of CRP and IL- 6 predict the development of type 2 diabetes mellitus [22]. Also, Liu, et al. confirmed the role played by TNF- $\alpha$, IL- 6 and CRP as an etiological factor for non-insulin dependent diabetes [23].

In this study VCAM-1, ICAM-1 and E-selectin level were significantly higher in diabetic group than the control group. Therefore, the results in this study are consistent with Meigs, et al. who reported that endothelial dysfunction predicts non-insulin dependent diabetes among women [19]. Also, Thorand, et al., supported the role of endothelial dysfunction in the pathogenesis of non-insulin dependent diabetes [24]. However, level of sE-selectin was found to be independently associated with diabetes $[25,26]$. In addition, the Women's Health Initiative Observational Study proved that found E-selectin could be considered as a predictor of diabetes among U.S.A. women [27].

The underlying mechanisms for increased rate of cardiovascular morbidity and mortality among diabetic patients are not fully elucidated, however elevated markers of systemic inflammation and endothelial dysfunction are associated with excess visceral adiposity [28]. Moreover, Goldberg stated that systemic inflammation affects platelet adhesion, oxidants production and platelet aggregation which induced cardiovascular disorders among diabetic patients [29]. This study has some limitations. First, it was not appropriate to carry out analyses by age group due to a reduction in a negligible sample size. Second, the subjects in this study were only Saudi subjects and capacity of insulin secretion and degree of obesity in Asians are known to be different from Western people, and thus our findings might not be applicable to Caucasians, therefore, a prospective future study is necessary to clarify this limitation.

\section{Conclusion}

There is a strong association between markers of endothelial dysfunction and systemic inflammation among obese patients with type 2 diabetes. Novel therapeutic measures to ameliorate endothelial dysfunction and systemic inflammation may be essential in clinical management for type 2 diabetic populations.

\section{Acknowledgment}

Author thanks physicians of the outpatient clinic and all the laboratory staff members at King Abdulaziz University Hospital, Jeddah, Saudi Arabia, for their skillful assistance in the clamp procedures of this article and is grateful for the cooperation of all participants in this study.

\section{References}

1. World Health Organization: Bode CD. Media Centre-Fact Sheets, Diabetes. 2011.

2. Basha B, Samuel SM, Triggle CR, Ding H. Endothelial dysfunction in diabetes mellitus: possible involvement of endoplasmic reticulum stress? Exp Diabetes Res. 2012; 2012: 481840
3. Havel PJ. Control of energy homeostasis and insulin action by adipocyte hormones: leptin, acylation stimulating protein, and adiponectin. Curr Opin Lipidol. 2002; 13: 51-59.

4. Dekker MJ, Lee S, Hudson R, Kilpatrick K, Graham TE, Ross R, et al. An exercise intervention without weight loss decreases circulating interleukin-6 in lean and obese men with and without type 2 diabetes mellitus. Metabolism. 2007; 56: 332-338.

5. Church TS, Thompson AM, Katzmarzyk PT, Sui X, Johannsen N, Earnest $\mathrm{CP}$, et al. Metabolic syndrome and diabetes, alone and in combination, as predictors of cardiovascular disease mortality among men. Diabetes Care 2009; 32: 1289-1294.

6. Kelley GA, Kelley KS. Effects of aerobic exercise on lipids and lipoproteins in adults with type 2 diabetes: a meta-analysis of randomized-controlled trials. Public Health. 2007; 121: 643-55.

7. Rosa Neto JC, Lira FS, Oyama LM, Zanchi NE, Yamashita AS, Batista ML, et al. Exhaustive exercise causes an anti-inflammatory effect in skeletal muscle and a pro-inflammatory effect in adipose tissue in rats. Eur $\mathrm{J}$ Appl Physiol. 2009; 106: 697-704.

8. Ruan H, Lodish HF. Insulin resistance in adipose tissue: direct and indirect effects of tumor necrosis factor-alpha. Cytokine Growth Factor Rev. 2003; 14: 447-455

9. Calabro P, Chang DW, Willerson JT, Yeh ET. Release of C-reactive protein in response to inflammatory cytokines by human adipocytes: linking obesity to vascular inflammation. J Am Coll Cardiol. 2005; 46: 1112-1113.

10. Tuomisto K, Jousilahti $P$, Sundvall J, Pajunen $P$, Salomaa V. C-reactive protein, interleukin- 6 and tumor necrosis factor alpha as predictors of incident coronary and cardiovascular events and total mortality. A population-based, prospective study. Thromb Haemost. 2006; 95: 511-518.

11. Pradhan AD, Ridker PM. Do atherosclerosis and type 2 diabetes share a common inflammatory basis? Eur Heart J. 2002; 23: 831-834.

12. Gómez JM, Vila R, Catalina P, Soler J, Badimón L, Sahún M. The markers of inflammation and endothelial dysfunction in correlation with glycated haemoglobin are present in type 2 diabetes mellitus patients but not in their relatives. Glycoconj J. 2008; 25: 573-579.

13. Ansar S, Koska J, Reaven PD. Postprandial hyperlipidemia, endothelial dysfunction and cardiovascular risk: focus on in cretins. Cardiovasc Diabetol. 2011; 10: 61 .

14. Cersosimo E, DeFronzo RA. Insulin resistance and endothelial dysfunction: the road map to cardiovascular diseases. Diabetes Metab Res Rev. 2006; 22: $423-436$.

15. Endemann DH, Schiffrin EL. Endothelial dysfunction. J Am Soc Nephrol. 2004; 15: 1983-1992.

16. Gómez JM, Sahún $M$, Vila R, Domènech $P$, Catalina $P$, Soler J, et al. Elevation of E-selectin concentrations may correlate with potential endothelial dysfunction in individuals with hypopituitarism during therapy with growth hormone. Curr Neurovasc Res. 2007; 4: 55-62.

17. Fowler M. Microvascular and macro vascular complications of diabetes. Clinical Diabetes. 2008; 26: 77-82.

18. de Jager J, Dekker J, Kooy A, Kostense P, Nijpels G, Heine R, et al. Endothelial dysfunction and low-grade inflammation explain much of the excess cardiovascular mortality in individuals with type 2 diabetes: the Hoorn Study. Arterioscler Thromb Vasc Biol. 2006; 26: 1086-1093.

19. Meigs JB, Hu FB, Rifai N, Manson JE. Biomarkers of endothelial dysfunction and risk of type 2 diabetes mellitus. JAMA. 2004; 291: 1978-1986.

20. Ye X, Franco OH, Yu Z, Li H, Hu FB, Liu H, et al. Associations of inflammatory factors with glycaemic status among middle-aged and older Chinese people. Clin Endocrinol (Oxf). 2009; 70: 854-862.

21. Swellam M, Sayed Mahmoud And M, Abdel-Fatah Ali A. Clinical implications of adiponectin and inflammatory biomarkers in type 2 diabetes mellitus. Dis Markers. 2009; 27: 269-278.

22. Pradhan AD, Manson JE, Rifai N, Buring JE, Ridker PM. C-reactive protein, 
interleukin 6, and risk of developing type 2 diabetes mellitus. JAMA. 2001, 286: 327-334.

23. Liu S. Markers That May Predict Diabetes In Still-Healthy People Identified Science Daily. 2007; 82: 211-218.

24. Thorand B, Baumert J, Chambless L, Meisinger C, Kolb H, Döring A, et al Elevated markers of endothelial dysfunction predict type 2 diabetes mellitus in middle-aged men and women from the general population. Arterioscler Thromb Vasc Biol. 2006; 26: 398-405.

25. Song Y, Manson JE, Tinker L, Rifai N, Cook NR, Hu FB, et al. Circulating levels of endothelial adhesion molecules and risk of diabetes in an ethnically diverse cohort of women. Diabetes. 2007; 56: 1898-1904.

26. Laaksonen DE, Niskanen L, Nyyssönen K, Punnonen K, Tuomainen TP Valkonen VP, et al. C-reactive protein and the development of the metabolic syndrome and diabetes in middle-aged men. Diabetologia. 2004; 47: $1403-$ 1410.
27. Ingelsson $\mathrm{E}$, Hulthe J, Lind L. Inflammatory markers in relation to insulin resistance and the metabolic syndrome. Eur J Clin Invest. 2008; 38: 502-509.

28. Leinonen E, Hurt-Camejo E, Wiklund O, Hultén LM, Hiukka A, Taskinen MR Insulin resistance and adiposity correlate with acute-phase reaction and soluble cell adhesion molecules in type 2 diabetes. Atherosclerosis. 2003; 166: 387-394.

29. Goldberg RB. Cytokine and Cytokine-Like Inflammation Markers, Endothelia Dysfunction, and Imbalanced Coagulation in Development of Diabetes and Its Complications. J Clin Endocrinol Metab. 2009; 94: 3171-3182.
Austin J Gastroenterol - Volume 4 Issue 2 - 2017

ISSN : 2381-9219 | www.austinpublishinggroup.com

Saiem Al-Dahr. (C) All rights are reserved
Citation: Saiem Al-Dahr MH. Inflammatory Biomarkers and Endothelial Dysfunction among Obese Patients with Type 2 Diabetes: A Correlational Study. Austin J Gastroenterol. 2017; 4(2): 1080. 